\title{
Retroperitoneoscopic Renal Biopsy in Children
}

\author{
Carlos M. Jesus, Hamilto Yamamoto, Paulo R. Kawano, Rodrigo Otsuka, Oscar E. Fugita
}

Department of Urology, School of Medicine, General Hospital, UNESP, Botucatu, Sao Paulo, Brazil

\begin{abstract}
Objective: We present our experience in a series of 17 consecutive pediatric patients submitted to retroperitoneal laparoscopic renal biopsy.

Materials and Methods: Retroperitoneal laparoscopic renal biopsy (LRB) was performed in 5 boys and 12 girls. Mean age was 8.1 years and age range from 2 to 12 . Two or three trocars were used to expose the inferior pole of the kidney, remove enough cortical parenchymal specimen and fulgurate the biopsy site. Assessment included surgical time, estimated blood loss, hospitalization period, analgesia requirements, complications and number of glomeruli present in the specimen.

Results: LRB was successfully performed in all 15 patients (88\%). In two cases, LRB was not possible to be performed. One patient was converted to a transperitoneal laparoscopy due to tear in the peritoneum. The other patient had had previous abdominal surgery and, during retroperitoneal balloon dilation, the peritoneum was opened and the open biopsy was performed. A third patient had postoperatively a perirenal hematoma, which was solved spontaneously. Complication rate was $17.6 \%$ ( $3 / 17$ cases). Mean operative time was 65 minutes, while mean estimated blood loss was $52 \mathrm{~mL}$, mean hospital stay was 2.2 days and mean analgesic requirement was $100 \mathrm{mg}$ of tramadol. The mean number of glomeruli present in the specimen was 60 .

Conclusion: Retroperitoneal laparoscopic renal biopsy in children is a simple, safe. Bleeding is still the most common complication. However, direct vision usually allows a safe control of this drawback. In our institution, laparoscopic approach is the chosen procedure in pediatric patients older than one - year - old.
\end{abstract}

Key words: renal biopsy; children; laparoscopy; complications

Int Braz J Urol. 2007; 33: 536-43

\section{INTRODUCTION}

Renal biopsy is an important procedure for renal disease investigation. Percutaneous needle renal biopsy (PNRB) is the most common technique to obtain renal tissue. However, there are absolute and relative contraindications such as solitary kidney, uncontrolled arterial hypertension, hemostasis disorders, renal artery aneurysm, Jehovah witness, percutaneous needle renal biopsy failure, morbid obesity and non-collaborative patients (1-4). In these situations, open renal biopsy (ORB) is the option through flank or posterior incision $(5,6)$.

As an alternative to ORB in selected cases, some authors propose transperitoneal (7) or retroperitoneal laparoscopic approach (8-12). Laparoscopy allows potential advantages such as less postoperative pain, better cosmetic results, short hospitalization and convalescence $(13,14)$.

Open renal biopsy was performed to obtain renal tissue samples in children before the laparoscopic 
approach. We believe this procedure is safer than PNRB. In 2002, with the advent of laparoscopy and considering its potential benefits, we standardized the renal tissue sample through retroperitoneal route in children.

\section{MATERIALS AND METHODS}

Twenty renal biopsies were performed from April 2002 to February 2006 in children younger than 12 -year old to different renal conditions. Seventeen children were submitted to retroperitoneal laparoscopic renal biopsy (LRB) and three were submitted to ORB. Large ascites in one patient, severe trombocitopenia in the second (fewer than 30,000 platelets) and low age (two-months-old) in the third child determined the choice for ORB.

The children's parents were informed about the procedure and the probability of choosing open surgery conversion. The study was evaluated and accepted by the ethics committee of the institution.

The procedure was performed under general anesthesia placing the Foley catheter in bladder and nasogastric tube. The patient was put in flank position in the renal side to be operated. The kidney bridge was elevated underneath the last ribs to increase the space between the costal margins and the iliac crest in order to create a larger retroperitoneal working area. Before the surgery, prophylactic antibiotics (cefalotin $50 \mathrm{mg} / \mathrm{kg} / 24 \mathrm{~h}$ ) were administered.
A 1.0 to $1.5 \mathrm{~cm}$ incision was made in the tip of the 12th rib in the retroperitoneum. Through this incision, the retroperitoneal area was dissected and the peritoneum pushed forward. An additional retroperitoneal space was completed using balloon dissection whose function was to increase the working space and promote the hemostasis after the digital dissection.

Afterwards, a $10 \mathrm{~mm}$ trocar was placed and retroperitoneal area was created with $\mathrm{CO}_{2}$ and a 10 to $12 \mathrm{~mm} \mathrm{Hg}$. Then, lower kidney pole was observed. A $5 \mathrm{~mm}$ trocar was placed in posterior lower axillary line, under laparoscopic view. Through the $5 \mathrm{~mm}$ trocar, scissors or biopsy grasper were used to perform $0.5 \mathrm{~cm}$ ellipsoid incision in lower renal pole or with a biopsy grasper. If necessary, a third $5 \mathrm{~mm}$ trocar was placed, behind the first one to facilitate renal surface exposition (Figure-1).

The biopsy bed was fulgurated with argon beam coagulator or pressed with gauze for 5 minutes. As a next step, oxidized cellulose could be used in biopsy bed. If there was no bleeding, retroperitoneum pressure was reduced to $5 \mathrm{mmHg}$ and now, a new hemostasia revision was done. No drain was left. The nasogastric tube and Foley catheter were withdrawn after surgery. Analgesia was endovenous with tramadol $(0.25 \mathrm{mg} / \mathrm{kg} /$ bolus $)$ for every patient requirement by endovenous infusion pump plus dipirona ( 50 $\mathrm{mg} / \mathrm{kg} / \mathrm{dose}$ every 8 hours). The post-operative follow-up evaluated operation time, blood loss, intra and post-operative complications, hospital stay, cumulative

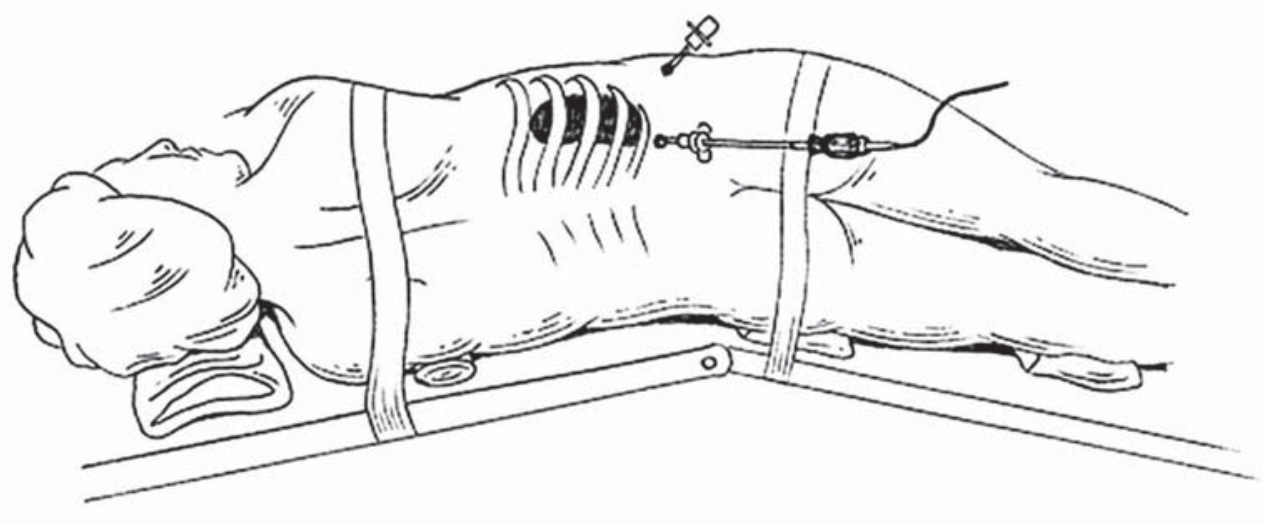

Figure 1 - Patient position in operative table for retroperitoneoscopic renal biopsy. 
analgesia measure, histopathological diagnosis and glomeruli number.

\section{RESULTS}

LRB was performed in 5 boys and 12 girls. Patient data are listed in Table-1. Age ranges from 2 to 12 years old (mean 8.1 years) and mean operative time was 65 minutes (40 - 180 minutes). Hospital stay was 2.2 days. Three patients had complications. The first one, a 2-year old boy had peritoneum rupture during digital maneuver to create retroperitoneal area, which did not allow the completion of the retroperitoneal procedure. This surgery was performed by transperitoneal laparoscopic approach, using an additional trocar in left side in abdomen. The second patient had a huge peritoneum rupture, in the beginning of the surgery, thus not allowing laparoscopic procedure. This patient had been submitted to a previous open surgery (left hemicolectomy) due to inflammatory bowel disease. In both cases the hole in peritoneum is not repaired with sutures. The third patient had morbid obesity, which made it difficult to find the kidney in surgery. He lost blood in the first postoperative day and a $300 \mathrm{~mL}$ - perirenal hematoma was observed by ultrasound, and it was solved spontaneously. Mean analgesic doses were $100 \mathrm{mg}$ of tramadol. All the samples presented renal cortex. Glomeruli mean per fragment was 60 (average 37 and 128).

\section{COMMENTS}

Renal biopsy is an important key in the diagnosis and treatment of some renal diseases. In some cases, flank incisions could lead to morbidity. Renal biopsy was reinforced after the report by Iversen \& Braun showing PNRB as a safe, easy and less morbid method (15).

Table 1 - Clinical features of patients submitted to retroperitoneal renal biopsy.

\begin{tabular}{|c|c|c|c|c|c|c|c|c|c|c|c|}
\hline Patient & Age & Gender & $\begin{array}{l}\text { Clinical } \\
\text { Diagnosis }\end{array}$ & BMI & $\begin{array}{l}\text { Operative } \\
\text { Time (min) }\end{array}$ & Trocars & $\begin{array}{l}\text { Stay } \\
\text { Time }\end{array}$ & $\begin{array}{c}\text { Analgesia } \\
\text { (tramadol) }\end{array}$ & $\begin{array}{c}\text { Operative } \\
\text { Bleeding }(\mathrm{mL})\end{array}$ & $\begin{array}{l}\text { Glomeruli } \\
\text { Number }\end{array}$ & Complications \\
\hline 1 & 7 & M & NS & 32 & 40 & 2 & 2 & 120 & 0 & 52 & - \\
\hline 2 & 2 & $\mathrm{~F}$ & NS & 23.6 & 85 & 3 & 2 & 60 & 25 & 37 & $\begin{array}{l}\text { transperitoneal } \\
\text { conversion }\end{array}$ \\
\hline 3 & 7 & $\mathrm{~F}$ & $\mathrm{ARF}$ & 24.5 & 50 & 2 & 2 & 200 & 0 & 46 & - \\
\hline 4 & 9 & $\mathrm{~F}$ & $\mathrm{LE}$ & 23.6 & 40 & 2 & 2 & 70 & 0 & 55 & - \\
\hline 5 & 12 & $\mathrm{~F}$ & $\mathrm{LE}$ & 55.6 & 180 & 3 & 2 & 150 & 100 & 150 & $\begin{array}{l}\text { perirenal } \\
\text { hematoma }\end{array}$ \\
\hline 6 & 11 & M & $\mathrm{ARF}$ & 21.8 & 80 & 2 & 2 & 0 & 20 & 55 & \\
\hline 7 & 10 & $\mathrm{~F}$ & HSP & 18.5 & 75 & 2 & 2 & 0 & 0 & 128 & \\
\hline 8 & 9 & $\mathrm{~F}$ & $\mathrm{ARF}$ & 24 & 60 & 2 & 2 & 200 & 100 & 55 & \\
\hline 9 & 6 & M & $\mathrm{ARF}$ & 24 & 60 & 2 & 2 & 140 & 0 & 80 & \\
\hline 10 & 4 & $\mathrm{~F}$ & NS & 25.7 & 73 & 2 & 3 & 0 & 100 & 100 & \\
\hline 11 & 7 & $\mathrm{~F}$ & NS & 13 & 52 & 2 & 2 & 200 & 0 & 28 & \\
\hline 12 & 9 & M & HSP & 15 & 55 & 2 & 2 & 70 & 50 & 35 & \\
\hline 13 & 10 & $\mathrm{~F}$ & NS & 13.8 & 60 & 2 & $*$ & $*$ & $*$ & 38 & $\begin{array}{c}\text { open } \\
\text { conversion }\end{array}$ \\
\hline 14 & 11 & $\mathrm{~F}$ & HSP & 14.7 & 40 & 2 & 2 & 0 & 0 & 50 & \\
\hline 15 & 12 & $\mathrm{~F}$ & $\mathrm{ARF}$ & 14.4 & 60 & 2 & 2 & 70 & 0 & 30 & \\
\hline 16 & 9 & $\mathrm{~F}$ & NS & 17.1 & 30 & 2 & 2 & 120 & 10 & 60 & \\
\hline 17 & 6 & M & NS & 16.1 & 75 & 2 & 2 & 125 & 40 & 30 & \\
\hline
\end{tabular}

$M=$ male $; F=$ female $; N S=$ nephrotic syndrome $; A R F=$ acute renal failure $; L E=$ lupus erythematosus $; H S P=H e n o c h-S c h o ̈ n l e i n$ purpura; $B M I=$ body mass index. 
Although PNRB is the standard procedure to obtain renal tissue samples nowadays, it is not indicated in different situations such as noncollaborative patients, failure to obtain samples for pathology tests, solitary kidney, morbid obesity and hematological disorders (1-4). In these cases, some authors suggest laparoscopic approach as an alternative to ORB $(7-12,16)$.

PNRB could be done in children, but there are some drawbacks. They need some kind of sedation or general anesthesia for renal biopsy to be done under computerized tomography or ultrasound. In addition, PNRB presents some risks, which could lead to renal bleeding, arterio-venous fistulas and renal aneurysms $(4,17,18)$. In laparoscopic approach, blood loss is minimized because biopsy bed is controlled quickly under direct view, which is not possible in PNRB. Another advantage of LRB is the high positivity about the renal samples (almost 100\%) different from the needle method, which is around $90 \%$ of renal fragments (12,16-18). We believe LRB eliminates the necessity of another procedure.

In our study, two complications could be avoided. In order to avoid peritoneum tears during digital maneuver to create retroperitoneal space, this procedure must be carried out carefully because children have a thin peritoneum. However, not all peritoneal incidental lesions need to convert to open or laparoscopic transperitoneal approach because there could be $\mathrm{CO}_{2}$ equivalence pressure between the intraperitoneal cavity and the retroperitoneum. Only in cases where there are big holes in the peritoneum, this maneuver could not be done, allowing the lowering of the peritoneal envelope on the retroperitoneal area, preventing the normal development of the procedure.

Caione et al. analyzed LRB in 22 children with the same parameters used by us (12). Data such as sample success and age were similar to our series. On the other hand, their operative time and hospital stay were shorter than ours according to Table-2.

As to the trocar numbers, we believe two are enough in most cases. In the beginning of our experience, we used three trocars. Usually, we only use the third trocar in hard cases, e.g. morbid obesity.

Obesity could complicate retroperitoneal access $(16,19,20)$. It occurred in an obese patient, leaving a perirenal hematoma. It is not clear if the bleeding site was the biopsy bed or the perinephretic fat. It is hard to reach the renal lower pole in these

Table 2 - Pre and postoperative clinical features and complications of patients submitted to laparoscopic renal biopsy.

\begin{tabular}{|c|c|c|c|c|c|c|c|c|c|}
\hline Author & Study & $\begin{array}{c}\text { Sample } \\
\text { Success }(\%)\end{array}$ & $\begin{array}{c}\text { Age } \\
\text { (years) }\end{array}$ & BMI & $\begin{array}{l}\text { Operative } \\
\text { Time (min) }\end{array}$ & Trocars & $\begin{array}{c}\text { Stay Time } \\
\text { (days) }\end{array}$ & $\begin{array}{c}\text { Operative } \\
\text { Bleeding }(\mathrm{mL})\end{array}$ & Complications \\
\hline Current series & 17 & 100 & 8 & 21 & 65 & $\begin{array}{l}2(88 \%) \\
3(12 \%)\end{array}$ & 2.2 & $\begin{array}{c}52 \\
(0-500)\end{array}$ & $\begin{array}{c}2 \text { peritoneum tears } \\
\text { 1perirenal hematoma } \\
(17.6 \%)\end{array}$ \\
\hline Caione et al. (12) & 20 & 100 & 9.2 & - & 40 & 2 & 1.2 & 0 & $\begin{array}{c}1 \text { peritoneum tear } \\
1 \text { conversion (obese } \\
\text { patient) }\end{array}$ \\
\hline Shetye et al. (16) & 74 & 96 & 45 & 47.4 & 123 & 5 & $\begin{array}{l}58 \% \text { discharge } \\
\text { in } 1 \text { day } \\
18 \% \text { discharge } \\
\text { in } 2 \text { days }\end{array}$ & $\begin{array}{c}67 \\
(5-2000) \\
\\
\\
\\
\\
\\
\end{array}$ & $\begin{array}{c}3 \text { hemorrhage } \\
\text { episodes }(25 \%) \\
2 \text { inadverted biopsies } \\
2 \text { unsuccessful } \\
\text { samples } \\
1 \text { bowel loop lesion } \\
6 \text { clinical } \\
\text { complications }(14.8 \%)\end{array}$ \\
\hline
\end{tabular}


cases. Caione et al. performed the only open surgery conversion in an obese child, due to the difficulty of finding the operation landmarks (12). Yap et al. suggested the intra-operative ultrasound use in morbid obese to make kidney location easier for biopsy taking (20). Shetye et al. reported unexpected spleen biopsy in two cases in LRB in obese patients, showing that, in these cases, it was harder to set anatomic landmarks, due to excessive retroperitoneal fat. In a similar way, these complications were minimized with intraoperative ultrasound. Complication rate in this series of 74 patients (aged 3 to 74 years old) was $20 \%$. The most frequent type of complication was hemorrhage, comprising $20 \%$ of all (16).

In our study, little analgesic was used and two children did not use it post - operatively. Cumulative analgesic average dose during hospital stay was 100 $\mathrm{mg}$ of tramadol and 500g of dipirone, which we believe to be very low. LRB complication rate ranges from 0.7 to $11 \%$ in adults $(4,17,18)$. LRB can be an alternative procedure, as it is minimally invasive, with low complication rate and high successful sampling rate (Table-2).

As far as we know, this is the only series that uses LRB solely in children under 12 - years - old, because we believe that only this age range can benefit from this procedure. Caione et al. performed the laparoscopic approach just where PNRB could not be applied, because of uncontrolled hypertension, hematological disorders, anti-platelet medications and anatomic abnormalities (12). In teenagers, PNRB is regarded as a better, less invasive method, which does not require either sedation or general anesthesia, since most patients are collaborative.

\section{CONCLUSION}

LRB in children is a safe and effective procedure. At present this approach is used in our institution in children older than one year-old and younger than 12 years-old, as well as in patients with contraindication to PNRB.

\section{CONFLICT OF INTEREST}

None declared.

\section{REFERENCES}

1. Bolton WK, Vaughan ED Jr: A comparative study of open surgical and percutaneous renal biopsies. J Urol. 1977; 117: 696-8.

2. Patil J, Bailey GL, Mahoney EF: Open-renal biopsy in uremic patient. Urology. 1974; 3: 293-6.

3. Schow DA, Vinson RK, Morrisseau PM: Percutaneous renal biopsy of the solitary kidney: a contraindication? J Urol. 1992; 147: 1235-7.

4. Kark RM, Muehrcke RC, Pollack VE, Pirani CL, Kiefer JH: An analysis of five hundred percutaneous renal biopsies. AMAArch Intern Med. 1958; 101: 439-51.

5. Almkuist RD, Buckalew VM Jr: Techniques of renal biopsy. Urol Clin North Am. 1979; 6: 503-17.

6. Hinman F Jr: Open renal biopsy. In: Atlas of Urologic Surgery. Philadelphia, WB Saunders. 1988; pp. 839-90.

7. Healey DE, Newman RC, Cohen MS, Mars DR: Laparoscopically assisted percutaneous renal biopsy. J Urol. 1993; 150: 1218-21.

8. Gaur DD: Laparoscopic operative retroperitoneoscopy: use of a new device. J Urol. 1992; 148: 1137-9.

9. Gaur DD, Agarwal DK, Khochikar MV, Purohit KC: Laparoscopic renal biopsy via retroperitoneal approach. J Urol. 1994; 151: 925-6.

10. Gimenez LF, Micali S, Chen RN, Moore RG, Kavoussi LR, Scheel PJ Jr: Laparoscopic renal biopsy. Kidney Int. 1998; 54: 525-9.

11. Rassweiler JJ, Seemann O, Frede T, Henkel TO, Alken P: Retroperitoneoscopy: experience with 200 cases. J Urol. 1998; 160: 1265-9.

12. Caione P, Micali S, Rinaldi S, Capozza N, Lais A, Matarazzo E, et al.: Retroperitoneal laparoscopy for renal biopsy in children. J Urol. 2000; 164: 1080-3.

13. Abbou CC, Cicco A, Gasman D, Hoznek A, Antiphon P, Chopin DK, et al.: Retroperitoneal laparoscopic versus open radical nephrectomy. J Urol. 1999; 161: 1776-80.

14. Doublet JD, Barreto HS, Degremont AC, Gattegno B, Thibault P: Retroperitoneal nephrectomy: comparison of laparoscopy with open surgery. World J Surg. 1996; 20:713-6.

15. Iversen $P, B$ run $C$ : Aspiration biopsy of the kidney. Am J Med. 1951; 11: 324-30.

16. Shetye KR, Kavoussi LR, Ramakumar S, Fugita OE, Jarrett TW: Laparoscopic renal biopsy: a 9-year experience. BJU Int. 2003; 91: 817-20.

17. Muth RG: The safety of percutaneous renal biopsy: an analysis of 500 consecutive cases. J Urol. 1965; 94: 1-3.

18. Diaz-Buxo JA, Donadio JV Jr: Complications of percutaneous renal biopsy: an analysis of 1,000 consecutive biopsies. Clin Nephrol. 1975; 4: 223-7. 
19. Chen RN, Moore RG, Micali S, Kavoussi LR: Retroperitoneoscopic renal biopsy in extremely obese patients. Urology. 1997; 50: 195-8.
20. Yap RL, Chan DY, Fradin J, Jarrett TW: Intraoperative ultrasound guided retroperitoneal laparoscopic renal biopsy in the morbidly obese patient. J Urol. 2000; 163: 1197-8.

\section{Correspondence address:}

Dr. Carlos Márcio Nóbrega de Jesus

Faculdade de Medicina de Botucatu, UNESP

Botucatu, SP, 18618-000, Brazil

Fax: + 55 143811-6271

E-mail: marcio@fmb.unesp.br

\section{EDITORIAL COMMENT}

Retroperitoneal endoscopic approach has gained popularity both worldwide and in our country including indications in pediatric cases (1-3).

Regarding the access, in general most comparative studies show no advantage for retroperitoneal to transperitoneal approach to kidney indications. In my opinion for kidney biopsy, retroperitoneoscopy offer advantage due to be a faster and direct procedure without violation of peritoneal cavity.

We reported the first series of this procedure in Brazil 5 years ago as an option for cases with high risk for bleeding, previous insufficient sample or when the technical conditions for ultrasound guided biopsy were not available $(4,5)$.

At learning curve, our team had one conversion because the kidney was small and difficult to locate. Peritoneal tears are relatively frequent and innocuous, but in our experience, there are no conversions due to this "complication". Some maneuvers as place an anterior trocar to displace peritoneum medially, puncture with intracath in the peritoneum or to do a big opening in anterior peritoneum can solve the peritoneal compression to the working space.
Accepted after revision:

February 28, 2007
Another important issue is to check the hemostasis before removing the trocars. Pressure of $\mathrm{CO}_{2}$ need to be reduced to $5 \mathrm{mmHg}$ and an inspection was done accurately. Additional cautery or a resin as surgicel or gelfoam can achieve a good hemostasis when necessary.

I agree with the authors that show that the samples are excellent for pathological analysis. This fact and an iterative anesthesia in children to do this procedure are the most important arguments to prefer the retroperitoneoscopic to needle biopsy in this age.

This report clearly confirms the growing indication of retroperitoneoscopic surgery in the modern urological armamentarium.

\section{REFERENCES}

1. Tobias-Machado M, Tulio Lasmar M, Rincon Rios F, Forseto PH, Vaz Juliano R, Roger Wroclawski ER: 6year experience with extra peritoneal lumbar laparoscopic surgery: indications, complications, and results in a reference Southamerican center. Arch Esp Urol. 2005; 58: 657-64.

2. Tobias-Machado M, Juliano RV, Gaspar HA, Rocha RP, Borrelli M, Wroclawski ER: Videoendoscopic 
surgery by extraperitoneal access: technical aspects and indication. Int Braz J Urol. 2003; 29: 441-9.

3. Tobias-Machado M, Cartum J, Santos-Machado TM, Gaspar HA, Simoes AS, Cruz R, et al.: Retroperitoneoscopic adrenalectomy in an infant with adrenocortical virilizing tumor. Sao Paulo Med J. 2002; 120: 87-9.
4. Tobias-Machado M, Pinto MA, Juliano RV, Cintra CC, Wroclawski ER: Retroperitoneoscopic renal biopsy. Int Braz J Urol. 2002; 28: 192-6.

5. Tobias-Machado M, Pinto MA, Juliano RV, Neto ACC, Wroclawski ER, Borelli M: Laparoscopic biopsy of the kidney: an option of access. J Endourol. 2000; 14 (suppl): 54.

Dr. Marcos Tobias-Machado Section of Urologic Oncology and Laparoscopy Department of Urology, ABC Medical School

Santo Andre, Sao Paulo, Brazil E-mail: tobias-machado@uol.com.br

\section{EDITORIAL COMMENT}

The authors are to be commended for their interesting and original series of 17 patients aged from 2 to 12 years-old undergoing retroperitoneoscopic renal biopsy (LRB) as an alternative to open renal biopsy (ORB). Three patients were contraindicated to the retroperitoneoscopic approach due to ascites, severe thrombocitopenia, and low age (two-month old).

There are some points however that should be discussed with the reader. Although the authors state that there are some drawbacks of percutaneous renal biopsy (PNRB) in children, and that LRB is the preferred method in their institution for renal sampling in children between 1 and 12 years, PNRB under ultrasound guidance continues to be the standard approach to allow histological diagnosis in children with evidence of renal disease.

While LRB requires general anesthesia, in a recent study Sinha et al. suggests that children older than five years of age may be selected on an individual basis for the biopsy to be performed under sedation as a day care procedure (1).
Although both ORB and LRB have the potential to minimize blood loss by quickly controlling the biopsy bed under direct vision, PNRB has achieved acceptable complication and bleeding rates of less than $5 \%(1,2)$, similar to the rates reported in LRB series $(3,4)$.

Failure to obtain adequate tissue for diagnosis may occur with both PNRB and LRB. A recent study has proposed that a success rate over $95 \%$ in obtaining adequate tissue for diagnosis is an acceptable standard for PNRB (2). The success rate in two series of LRB by Shetye et al. (3) and Caione et al. (4) were respectively $96 \%$ and $95 \%$. Even though LRB allows for biopsy of the kidney under direct vision, failure to obtain adequate tissue for diagnosis may occur mainly in obese patients due to excessive retroperitoneal fat and bleeding, with poor visualization of the laparoscopic field $(3,4)$. These patients may require open conversion or additional procedures.

It should be emphasized that PNRB is the preferred method for obtaining renal biopsy in chil- 
dren as long as there are no contraindications. LRB should be indicated as an alternative to ORB when there are contraindications to PNRB.

\section{REFERENCES}

1. Sinha MD, Lewis MA, Bradbury MG, Webb NJ: Percutaneous real-time ultrasound-guided renal biopsy by automated biopsy gun in children: safety and complications. J Nephrol. 2006; 19: 41-4.
2. Hussain F, Watson AR, Hayes J, Evans J: Standards for renal biopsies: comparison of inpatient and day care procedures. Pediatr Nephrol. 2003; 18: 53-6.

3. Shetye KR, Kavoussi LR, Ramakumar S, Fugita OE, Jarrett TW: Laparoscopic renal biopsy: a 9-year experience. BJU Int. 2003; 91: 817-20.

4. Caione P, Micali S, Rinaldi S, Capozza N, Lais A, Matarazzo E, et al: Retroperitoneal laparoscopy for renal biopsy in children. J Urol. 2000; 164: 1080-3.

\section{Dr. Frederico R. Romero \&}

Dr. Thadeu Brenny Filho

Department of Urology Hospital São Vicente

Curitiba, PR, Brazil

E-mail: frederico.romero@gmail.com 